\title{
CAN DEPOPULATED VILLAGES BENEFIT FROM THE SOCIAL AND ECONOMIC INCORPORATION OF ETHNIC AND IMMIGRANT COMMUNITIES? A SURVEY FOR BULGARIA
}

\author{
N. Georgieva-Stankova, Y. Yarkova, E. Mutafov* \\ Faculty of Economics, Trakia University, Stara Zagora, Bulgaria
}

\begin{abstract}
One of the greatest problems faced by rural areas in Bulgaria today is depopulation. The main research question posed in this paper is whether such depopulated regions can benefit from the social and economic integration of ethnic and immigrant communities. A survey on public opinion was conducted in two regions: one developed (Stara Zagora District), and one lagging (Vidin District). It focused on the willingness of local communities to "welcome" newcomers, to cohabit with them and their awareness of the possibility of enriching local cultures with their specific cultural traditions and experience. Results show varying tendencies, depending on the regional socio-economic level of development and degree of integration of the group. The survey directs the attention to significant social distances emerging in various regional communities between local populations, ethnic and/or immigrant communities. Conclusions reached show that ethnic and immigrant communities can be an important social and economic resource for Bulgarian villages. Nevertheless, this requires work predominantly on the structural level for providing opportunities and eliminating disadvantages, involving the introduction of improved integration and discrimination policies, legal framework and market opportunities, in order to foster better interethnic communication and trust, as an intrinsic quality of social capital, for overcoming existing barriers.
\end{abstract}

Key words: Depopulation, Rural areas, Socio-economic integration, Regional development

\section{INTRODUCTION}

Depopulation - main challenges faced by Bulgarian villages and rural areas

Villages and rural areas fall into the agenda of various analyses, assessments and policies. They present a research field for the study and analysis of new models of economic, civil and social behavior, and as such, remain at the center of our attention, not only as a source of agricultural products and foodstuffs, but as an asset and social welfare, with their unquestionable values - natural environment and landscape, open spaces, unique way of life, material and spiritual culture, place for recreation, tourism and rest. These specific territorial units do not remain isolated from global processes and challenges (climate changes, exploitation of natural resources, aging of the population, migration etc.), which create barriers for their sustainable and balanced development.

*Correspondence to: Emil Mutafov, Faculty of Economics, Trakia University, Stara Zagora, Bulgaria,mutafov@uni-sz.bg
Therefore, we need to seek ways to convert such barriers into possibilities, in order to preserve and revive them.

Demographic issues are some of the main challenges faced by the EU, with Bulgaria being one of the most affected countries. Two Bulgarian districts are quoted as regions with the highest degree of depopulation - Vidin (minus 17\%o) and Montana (minus 15\%o) (1). Bulgarian villages are a typical example of negative demographic processes. A sharp drop in population size in villages was registered between 2007 and 2012, both in rural areas $-13 \%$, and in Bulgaria as a whole $-12 \%$ (2). Compared to mid-20- ${ }^{\text {th }}$ century tendencies, the population in rural areas declined by $60 \%$. Towards December $31^{\text {st }} 2013,73.0 \%$ of the country's population lived in urban areas, and $27.0 \%$ in the villages. There are 5, 268 populated settlements in Bulgaria, of which 257 are cities and 5,011 villages (3). 
Table 1. Distribution of the population by region and type of settlement (2012)

\begin{tabular}{|c|c|c|c|c|c|c|}
\hline & Cities & & Villages & & Total & \\
\hline \multicolumn{7}{|c|}{ Population (in thousands, \%) } \\
\hline Rural areas & 1382 & $48.5 \%$ & 1468 & $51.5 \%$ & 2850 & $100.0 \%$ \\
\hline City areas & 3926 & $88.5 \%$ & 509 & $11.5 \%$ & 4435 & $100.0 \%$ \\
\hline Total & 5308 & $72.9 \%$ & 1977 & $27.1 \%$ & 7285 & $100.0 \%$ \\
\hline
\end{tabular}

The distribution of the population in populated areas at the end of 2013 was the result of its natural and mechanical movement, but also of the administrative changes in the country's settlement structure. The number of depopulated settlements was 169 at the end of the year. In 2013 only, the Council of Ministers decided to close down 10 settlements, 6 of which were closed by merging with another populated area.

A substantial part of the population in rural areas consists of ethnic minority groups, traditionally Roma and ethnic Turks, enlarged by incoming refugees and new immigrants in recent years. The successful integration of such groups in these regions may solve many demographic problems, contribute to their re-population, social and economic revival, and enrich local cultures.

Literature on ethnic entrepreneurship and migration studies explores the interplay of structural and cultural conditions for the successful socio-economic integration of ethnic and immigrant communities (4-8). While the socalled 'disadvantage theory' (5) focuses on deficiencies as part of the human capital of immigrant groups (i.e. language skills, education and experience), poverty, discrimination and lack of knowledge of the local culture (4), the cultural theory emphasises the particular cultural traits and experience that ethnic and migrant groups may be equipped with (i.e. hard work, acceptance of risk, ethnic networks, etc.) $(4,5)$, which may facilitate ethnic entrepreneurship and successful integration. The interactive model developed by Waldinger, Aldrich and Ward (7), asserts that "opportunity structures and ethnic resources constantly interact" (4), which may guarantee or impede the success of an ethnic enterprise (4). This model deals with the existing opportunity structures (market conditions, access to ownership, job market conditions and provisions of the legal framework), interacting with the ethnic resources (cultural traditions and ethnic social networks) (4). The mixed embeddedness model further develops the ethnic resources and opportunity structures model by highlighting several factors influencing ethnic entrepreneurship (4). These are the structures of the local economy, legal and institutional factors, as well as regional distinctiveness $(4,8)$. The specific location, characteristics of the local ethnic community and ethnic networks are also important factors (4). Last but not least, comes discrimination by host societies, but also through the local community (4).

The current research discusses the nature of some opportunity structures (such as regional development, demographic factors, land ownership, legal framework, market opportunities, etc.), and the existing predispositions of the local population for accepting ethnic and immigrant communities. However, the general focus of the survey is on the willingness of local communities to "welcome" newcomers, to cohabit with them and their awareness of the possibility of enriching local cultures with their specific cultural traditions and experience. Tendencies are measured as varying according to regional socio-economic development, related to the degree of integration of the group, a dependency established by previous research $(9,10)$. The survey directs the attention to significant social distances emerging in various regional communities in recent years between local population, the ethnic and/ or immigrant Other, comparing the results with previous national surveys on interethnic distances and ethnic stereotypes (11-15).

The goal of the survey we have conducted was to find the answer to some key research questions, concerning public opinion on the possibility of contribution of ethnic and immigrant communities in solving the problems of depopulation in rural areas, and to come up with proposals for any specific measures for the integration of these communities, with the idea to limit the depopulation of Bulgarian villages and revive parts of these settlements.

Our main argument is that ethnic and refugee/immigrant groups could partially 
contribute to the revival of depopulated villages by bringing in their skills, traditions and professional experience for the diversification of the local economies. However, the main obstacles can be related to certain structural disadvantages, like insufficient integration policies and lack of adequate solutions for problematic areas, as well as public attitudes with regard to using the potential of these specific social groups.

\section{The integration of ethnic and immigrant communities in Bulgaria}

A substantial part of the Roma population in Bulgaria lives in rural areas, although there is a marked tendency towards urban migration among them (16). "The National Roma Integration Strategy of the Republic of Bulgaria (2012-2020) "(17) indicates that spatial segregation, social isolation and deterioration in living conditions are serious structural disadvantages for Roma, especially in rural areas. Although urban migration processes among Roma are less expressed, compared to ethnic Turks and Bulgarians, the share of children and adolescents below 19 years of age living in rural areas is higher amongst Roma (17). Roma used to fill and important economic niche in the past with their specific traditional occupations by exploiting natural resources and providing different services to society (18-22). While state socialist polices sedentarised Roma in the late 1940s and made them part of the proletariat, providing permanent employment and almost completely eliminating poverty, the neoliberal transformation made Roma redundant, after the closing down of the state factories they were previously employed in. New integration policies, therefore, should strive at achieving higher employability of the Roma population and utilizing them as an important social and economic resource for the national economy, especially considering the serious problem of growing aging population in Bulgarian villages. Successful social inclusion of the Roma may contribute as a consequence to the re-population and revival of some rural regions.

Assessing the economic effects of potential Roma integration in Bulgaria, a survey conducted by the Open Society Institute (OSI) in Sofia (23), established that the total cost of Roma integration will not be very high, if suitable reforms, aiming social inclusion, elimination of existing structural obstacles and limitations are developed and implemented. The
GEORGIEVA-STANKOVA N., et al.

positive social benefits of Roma integration are considered substantial and exceed material costs by 20-30 times, not counting the benefits derived from the long-term rise in the educational level of Roma children (23). It is maintained that "owing to saved social benefits, resulting in decreased loss of efficiency, increased working hours and generated income, lower mortality and criminal rates, the social benefits from the complete integration of the Roma could equal between 15 and 30 billion BGN" for a 10 - year period (23).

The Turkish and Muslim population, living in certain regions of the country, represents another extremely valuable resource, with good traditions and skills in specific agricultural sectors in Bulgaria. According to official data, the ethnic Turkish population in Bulgaria is more numerous than the Roma $(588,024)$, and represents $9.4 \%$ of the total population (16). It is concentrated to a large extent in the rural, mountainous and hilly regions, being primarily engaged in agriculture, forestry, the textile and tobacco industries. Tobacco producers lost traditional markets in the former Soviet Union after 1989, which triggered serious processes of impoverishment among the ethnic Turkish population. Despite the fact that Bulgarian ethnic Turks gained considerable rights as a minority, their social and economic status deteriorated significantly after the changes, due to high unemployment rates (up to $80 \%$ in certain regions) and mass impoverishment, leading to new migration waves to Turkey and a number of EU countries (24). Generally, the regions with mixed population in the country are characterized by lower income and investment rates and higher state-aid dependency (24). Other problems exist in terms of infrastructure, land privatization, the educational and professional profiles of Turkish minority communities (24). However, young ethnic Turks have demonstrate increased interest and motivation in education in recent years, in comparison with other ethnic minorities, in the attempt to overcome negative regional restrictions and find better employment (25). Assiduousness and hard-work are established as their most valuable assets by in-group identification (25), which is also considered a distinctive mark of the Turkish population, according to macrosocial perceptions, in combination with other qualities, such as greater industriousness and business orientation (12). 
Another significant change involves tendencies towards overcoming the traditional patriarchal family model among young ethnic Turks and their drawing level with their Bulgarians peers (25). However, although minority Turks may tend to seek employment outside their birthplace (in the country or abroad), they still remain very strongly attached to it, as $89 \%$ of those surveyed pointed out their home town/region as their prioritised identity 25). At the same time, considering internal migration processes, the ethnic Turks carry the highest potential (45\%), compared to Bulgarians (37\%) and Roma (29\%) (25). The reasons for such migration tendencies are socio-economic - finding better employment and achieving a higher living standard (25).

Alexey Pamporov gives us yet a different view, by tackling an interesting phenomenon in recent years - a decrease in the number of Pomaks and Turks (primarily as a result of external migration), and increase in the relative share of Roma, in spite of declining total numbers of Roma population (13). Together with the general decline in the relative share of all ethnic minority groups, there is also a discernible growth in the relative share of people who had not declared their identity - 27 times higher $(683,590-9.3 \%$ of the country's population) in 2011, provoked by existing social fear, rather than freedom, as the author explains - a fear of being different, of the methods applied by state administration and institutions for storing information, handling documentation and archive files, of their indifference to hate speech in the media and to xenophobic discourse in the political and public sphere in general (13).

Another extremely serious issue is the problem with the integration of refugee and immigrant communities that escalated with the outset of the Syrian crisis in 2011. It has triggered major integration issues requiring intervention, such as the necessity of adequate and timely political reaction, suitable legislative changes to limit financial misappropriation and corruption in funding integration programs, as well as objective and unbiased media coverage of all issues associated with immigrants and refugees, in order to create a better atmosphere of tolerance and public latitude (26). Unfortunately, the Law on Asylum and Refugees (LAR), adopted on May 16, 2002, and the Law for Amendments to LAR in 2013, have been severely criticized by the European Commission, some human rights and nongovernmental organizations, for existing
GEORGIEVA-STANKOVA N., et al. inconsistencies with international legal treaties regarding the limiting of freedom of movement of refugees and introducing a closed-type accommodation for them in contradiction to EU requirements, as well as for obstructing the speed and efficiency of the legal defense (26). The lack of timely provision of the necessary EU funds for handling the refugee crisis in the country also derives from the delayed reaction of the state (26). Scandals, unveiled by the media related to various corruption schemes for draining EU funds and budget money, have only caused additional complications in solving the refugee crisis and delayed integration processes (26). All arguments above generate feelings of chaos and public disbelief that authorities are able to deal with the growing crisis (26). According to experts, "lack of the country's preparedness to handle the refugee crisis is most clearly evident from three extremely important directions, affecting foreigners and society as a whole: the conditions in refugee camps, media coverage of the problem and integration"(26). The media play an essential role in constructing the image of the immigrant/refugee as a serious rival in labour market competition, a threat to national security, the social system and Bulgarian identity (26). They have the potential to shape public attitudes towards new immigrants, especially by providing air-time to nationalist parties and political leaders, who mistake unbridled hate speech for freedom of speech (26). The consequences of such irresponsible media conduct and lack of adequate institutional and public response could result in more serious and long-term social problems that can hamper real integration processes (26). Criticism is further aimed at the Council of Ministers' autocracy and their lack of coordination with local authorities in dealing with refugee problems. All these lead to further aggravation of the conflict and new xenophobic displays. In the current situation, it is considered extremely important to address the following questions, also valid for the present research: "Will Bulgaria be able to acknowledge these people as a potential resource, in view of its aging population, deserted regions and demographic crisis, or whether it will allow their marginalisation and transformation into a problem"(26).

Despite promises held by the potential benefits carried by integration policies aimed at the three communities named above, and the assets derived from their human capital for rural areas, 
GEORGIEVA-STANKOVA N., et al.

their successful implementation may be seriously obstructed by growing negative public attitudes in the context of a deepening social and economic crisis. There are some worrisome tendencies that register continuous increase of social distances in the last 25 years towards Roma, Turks, Jews and the new immigrants coming from non-EU countries. Previous research $(14,15)$, establishes that the most significant social distances emerge between Roma and the rest of society on all issues, involving marriage, friendship, social contacts, business partnership or cohabitation. Data from a more recent social-distance survey conducted by the OSI, reveal that Bulgarians are most tolerant towards EU citizens, as representatives of "the white race" (such as British and Russians), followed by a number of other Slavic groups (Bessarabian Bulgarians, Macedonians, Serbs and Ukrainians) and traditional minorities, (such as Pomaks, Turks, Armenians, Jews or Romanians) (12). "Unwelcomed" are the Chinese and the Roma, and "totally unwelcomed" are the new minorities of African origins, the Muslim immigrant groups (Arabs, Albanians and Kurds) and the Vietnamese. The Roma are amongst the least prestigious groups, whilst the ethnic Turks are not as positively welcomed as shown in previous research (12).

The growth in negative tendencies results from considerable changes in the macrosocial context. The decrease in economic development and public welfare lead to more pronounced tendencies towards erecting ethnic boundaries and growing social distances. Ethnic minority and immigrant groups, if well-integrated, can be an important asset for the country's economy and depopulated rural areas, with their youthful demographic potential, specific social and cultural capital. Nevertheless structural disadvantages on national level related to dysfunctional institutional practices, poor legislation, lack of coordination between authorities, corruption and discrimination, interacting with the poor socio-economic level of development of the regions, inhabited by these groups, can be seen as impeding integration processes and benefitting from their potential. Integration processes of minority groups in society can be deemed as twofold: successful social and labour-inclusion policies can contribute to guaranteeing some basic democratic rights and values; simultaneously, this could alleviate social tensions and improve welfare for the group and society as a whole, while enriching it with their specific culture and experience.

\section{METHODOLOGY}

The tasks for accomplishing of the research goals include: 1) selecting the research regions; 2) developing the survey questionnaires and conducting fieldwork research; 3) processing and analyzing the information gathered from the survey questionnaires.

The regional cut in the research methodology is based on the Gross Domestic Product per capita in Bulgaria. The area of research includes two regions: 1) an example of a well developed region, the District of Stara Zagora, which comes fifth in the GDP growth rate per capita out of 28 districts $(27,2)$ and Vidin District, as an example of a lagging region, which has the lowest GDP per capita in the country.

The quantitative empirical research is based on a standardized sample public consultation through a survey questionnaire conducted in the period May - August 2014, including 146 respondents, where the number of valid ones was 145 . The research covered two groups of respondents from the two selected regions respectively -110 respondents from Stara Zagora District and 35 respondents from Vidin District.

The subject of this research covers issues related to the public opinions on using the potential of specific social groups that can be attracted and settled, thus contribute to the revival of depopulated Bulgarian villages. The body of this research includes analyzed results on the following questions: 1) "I would live in a village that is inhabited by"; 2) "The settlement of refugees and immigrants could help to revive the depopulated Bulgarian villages by bringing in new business experience and cultural traditions"; 3) "Providing land to the Roma could help for their better social and economic integration and contribute to the economic boost of the villages".

The objects of the current research are representatives of people in working age and their demographic characteristics, which are given in Table 2. 
Table 2. Demographic characteristic of the respondents

GEORGIEVA-STANKOVA N., et al.

\begin{tabular}{|c|c|c|c|c|}
\hline \multicolumn{3}{|c|}{ Region } & \multicolumn{2}{|c|}{ Gender } \\
\hline 1 & Developed & $76.00 \%$ & \begin{tabular}{l|l}
1 & Men \\
\end{tabular} & $41.80 \%$ \\
\hline 2 & Lagging & $24.00 \%$ & \begin{tabular}{l|l|}
2 & Women \\
\end{tabular} & $58.20 \%$ \\
\hline & Total & $100.00 \%$ & Total & $100.00 \%$ \\
\hline \multicolumn{3}{|c|}{ Education } & \multicolumn{2}{|c|}{ Age } \\
\hline 1 & Higher & $24.00 \%$ & \begin{tabular}{l|ll}
1 & 18 & -25
\end{tabular} & $40.40 \%$ \\
\hline 2 & Semi-higher & $6.20 \%$ & \begin{tabular}{l|l|}
2 & $26-35$ \\
\end{tabular} & $33.60 \%$ \\
\hline 3 & Secondary & $69.10 \%$ & \begin{tabular}{|l|l|}
3 & $36-50$ \\
\end{tabular} & $15.80 \%$ \\
\hline 4 & Primary & $0.70 \%$ & \begin{tabular}{l|l|}
4 & $51-60$ \\
\end{tabular} & $10.20 \%$ \\
\hline & Total & $100.00 \%$ & Total & $100.00 \%$ \\
\hline \multicolumn{5}{|c|}{ Marital Status } \\
\hline \multicolumn{4}{|c|}{1 Married, no children } & $6.20 \%$ \\
\hline 2 & \multicolumn{3}{|c|}{ Married, with children } & $30.80 \%$ \\
\hline \multirow[t]{2}{*}{3} & \multicolumn{3}{|l|}{ Single } & $63.00 \%$ \\
\hline & \multicolumn{3}{|l|}{ Total } & $100.00 \%$ \\
\hline \multicolumn{5}{|c|}{ Ethnic group } \\
\hline 1 & \multicolumn{3}{|l|}{\begin{tabular}{l|l}
1 & Bulgarian \\
\end{tabular}} & $89.00 \%$ \\
\hline 2 & \multicolumn{3}{|l|}{ Turkish } & $6.20 \%$ \\
\hline 3 & \multicolumn{3}{|l|}{ Roma } & $3.40 \%$ \\
\hline \multirow{2}{*}{\multicolumn{3}{|c|}{\begin{tabular}{|l|l|}
4 & Other \\
& Total \\
\end{tabular}}} & & $1.40 \%$ \\
\hline & & & & $100.00 \%$ \\
\hline \multicolumn{5}{|c|}{ Religion } \\
\hline 1 & \multicolumn{3}{|c|}{ Orthodox Christian } & $82.90 \%$ \\
\hline 2 & \multicolumn{3}{|l|}{ Catholic } & $2.10 \%$ \\
\hline 3 & \multicolumn{3}{|l|}{ Muslim } & $6.20 \%$ \\
\hline 4 & \multicolumn{3}{|c|}{ Other Christian religion } & $2.10 \%$ \\
\hline \multirow[t]{2}{*}{5} & \multicolumn{3}{|l|}{ Atheist } & $6.80 \%$ \\
\hline & \multicolumn{3}{|l|}{ Total } & $100.00 \%$ \\
\hline \multicolumn{5}{|c|}{ Social status } \\
\hline 1 & \multicolumn{3}{|l|}{ Wealthier } & $4.20 \%$ \\
\hline 2 & \multicolumn{3}{|l|}{ Middle class } & $79.80 \%$ \\
\hline 3 & \begin{tabular}{|l|l|}
3 & Poorer \\
\end{tabular} & & & $16.00 \%$ \\
\hline & Total & & & $100.00 \%$ \\
\hline & & Social gri & up & \\
\hline 1 & Working & & & $45.90 \%$ \\
\hline 2 & Student & & & $38.40 \%$ \\
\hline 3 & Studying and & & & $6.80 \%$ \\
\hline 4 & Unemployed & & & $5.50 \%$ \\
\hline 5 & Representativ & & & $2.70 \%$ \\
\hline 6 & Indigent or sc & & & $0.70 \%$ \\
\hline & Total & & & $100.00 \%$ \\
\hline
\end{tabular}

When analyzing the information from the poll, we have used descriptive statistical methods and means for finding cause and effect connections. The $\chi$ 2-method was used in our two dimensional frequency distribution for analyzing the nature of the connection - regular or random, since data was presented by weak scales.

\section{RESULTS}

Table 3 shows the descriptive statistical results with average values of the respondents' general attitude towards different ethnic groups as possible residents of the villages they may choose to settle in. They reveal that the highest average value (4.04 of maximum 5) is for villages with Bulgarian population, which speaks of a considerable preference for villages with Bulgarian population. The next highest value is for EU residents (value 2.45), which is closer to the results showing preference for this group. The lowest value is for the refugee group (1.43), which is rather an expression of dislike; 
not much different is the result for the Roma ethnic group (1.53). Less preferred ethnic groups also include ethnic Turks and settlers from nonEU countries. The results of this social survey
GEORGIEVA-STANKOVA N., et al. match the results of the Open Society Institute (12) and show permanent (even deepening) tendencies with respect to the social distances between different ethnic groups.

Table 3. Average values for respondents' attitude towards different ethnic groups as residents of villages

\begin{tabular}{|l|l|c|l|}
\hline $\mathbf{N}$ & \multicolumn{1}{|c|}{$\begin{array}{c}\text { Possible } \\
\text { answers }\end{array}$} & $\begin{array}{c}\text { Average } \\
\text { value }\end{array}$ & \multicolumn{1}{c|}{ Corresponding response } \\
\hline 1 & Bulgarians & 4.04 & "Considerable preference" \\
\hline 2 & Roma & 1.53 & Between "Negative preference" and "Low preference" \\
\hline 3 & Ethnic Turks & 1.79 & "Low preference" \\
\hline 4 & From EU & 2.45 & Between "Low preference" and "Moderate preference" \\
\hline 5 & Non - EU & 2.13 & "Low preference" \\
\hline 6 & Refugees & 1.43 & "Negative preference" \\
\hline
\end{tabular}

More detailed information about the distribution of the answers in classes/groups of residents is given by the one-dimensional distribution of respondents' answers in Table 4.

Table 4. "I would live in a village inhabited by" - distribution of respondents' answers

\begin{tabular}{|r|l|r|r|r|r|r|r|}
\hline $\mathbf{N}$ & Possible answers & Bulgarians & Roma & Turks & \multicolumn{1}{c|}{ EU } & Non-EU & Refugees \\
\hline 1 & No preference & $4.20 \%$ & $11.50 \%$ & $10.90 \%$ & $8.80 \%$ & $10.20 \%$ & $15.20 \%$ \\
\hline 2 & Negative preference & $5.60 \%$ & $38.10 \%$ & $31.90 \%$ & $16.10 \%$ & $19.70 \%$ & $44.20 \%$ \\
\hline 3 & Low preference & $1.40 \%$ & $42.40 \%$ & $36.20 \%$ & $21.20 \%$ & $32.80 \%$ & $30.40 \%$ \\
\hline 4 & Moderate preference & $9.60 \%$ & $3.60 \%$ & $11.60 \%$ & $32.80 \%$ & $24.20 \%$ & $6.60 \%$ \\
\hline 5 & Considerable preference & $29.20 \%$ & $2.20 \%$ & $7.20 \%$ & $18.20 \%$ & $10.20 \%$ & $0.00 \%$ \\
\hline 6 & Decisive factor to have only one origin & $50.00 \%$ & $2.20 \%$ & $2.20 \%$ & $2.90 \%$ & $2.90 \%$ & $3.60 \%$ \\
\hline & Total & $100.00 \%$ & $100.00 \%$ & $100.00 \%$ & $100.00 \%$ & $100.00 \%$ & $100.00 \%$ \\
\hline
\end{tabular}

The total portion of respondents, who prefer villages with Bulgarian population is $90.3 \%$, half of them point out that this is a decisive factor for choosing a settlement and those that have low preference are less than 1 on every 100 questioned. As for the Roma population, one third of the respondents are explicit that they do not wish to live in a populated area predominantly inhabited by this ethnic group. It is worth pointing out two factors which should not to be taken lightly: 1) the share of people preferring Roma population $(50.4 \%)$ is considerably higher than the portion of respondents with Roma origins (3.4\% - see Table 2) and of the total share of respondents from different ethnic groups than Bulgarian (11\% see Table 2), which is a sign of social acceptance. 2) $11.5 \%$ have no preferences, which should be taken as acceptance rather than rejection, i.e. we could say that almost $62 \%$ declare their preparedness to live with Roma. In the case of expressed attitude towards living together with the ethnic Turkish minority, bigger weight is given to acceptance (57.2\%), however, with a predominance of people with low preference - more than one third. Here again, one not so small portion (11.5\%) have no claims against co-habiting with this minority group.

Members of EU countries find approval in three quarters of the interviewed as potential residents of villages. Non-EU citizens are also accepted with the support of more than two thirds of the respondents, although the biggest portion is of those, who show low preference, adding those with no preferences to the same group.

Negative attitudes towards refugees stand out (approximately 60\%), and even those who stated preference for them, belong to the group with the lowest level of preference for cohabitation; however, a hidden potential for support could be found again in the group of people who have no preferences for this ethic group as potential inhabitants of Bulgarian villages. These results confirm the dominant negative tendencies towards refugees, immigrants and ethnic Turks, already evident from the Open Society Institute survey (12). 
GEORGIEVA-STANKOVA N., et al.

However, attitudes towards the Roma deserve special attention. According to Pamporov's research (12), the Roma are the least preferred as marital partners (together with a number of immigrant groups from Africa and Asia). The preference for living together with Roma in one neighborhood has severely dropped to $30.2 \%$ in the last two decades, in comparison with similar data from previous years: $52 \%$ (1992), 40\% (1994), 32\% (1997) and 41\% (May 2007) (12). The author also states that this difference is the result of considerable changes in the social context in the country (12). Earlier research (11) also shows that Bulgarians expressed general preference for living with Turks (between 80$89 \%$ ) and lesser with Roma (between 66-76\%) (12). However, in 2007, there was a significant drop in preferences for cohabiting with ethnic minorities, and now only $58.2 \%$ of the Bulgarians agreed to have Turks as their coresidents and $55.8 \%$ of the Roma as such (12). In this respect, the present research shows insignificant drop with a little more than one percent in the desire for cohabitation with the ethnic Turkish minority (57\% in 2014), while the desire for living together with Roma has surprisingly increased by more than $6 \%(62 \%)$. A possible partial explanation for this tendency, to accept Roma as cohabitants, could be found in the increasing refugee wave in recent years and the establishment of refugees and immigrants as considerably unfavoured for cohabitation $(60 \%)$, in comparison with other more familiar local ethnic groups. According to Pamporov's research (12), even more undesired for cohabitation than the Roma are some immigrant groups, such as the Vietnamese, Arabs, Albanians, "Negros" and Kurds, tested on the basis of the Bogardus social distance scale. However, when speaking about Roma coming from different countries, or even from different regions of the country, then the Roma remain the most undesirable group as neighbors, which may lead to possible ethnic tension, due to existing differences in the social and economic status of the locals and newcomers (12). In other words, this juxtaposition between "locals" vs. "foreigners", could have serious explanatory potential for a fictitious acceptance of the Roma in the research, i. e. showing preference for a more familiar (and at places partially integrated) ethnic minority, instead of the uncertainty of cohabiting with the unknown Other.

One-dimensional distribution of opinions on the following statement: "The settlement of refugees and immigrants could help to revive depopulated Bulgarian villages, by bringing in new business skills and cultural traditions" shows that half of the answers demontrate disagreement, and those who agree, accept this statement only to a certain extent. On the one hand, the fact that $10 \%$ of the people have no opinion can be taken as unfavorable, which speaks of the lack of information and awareness of the existing opportunities, but on the other, this can be taken as an opportunity for future work through awareness-raising programs and influencing public attitudes.

The structure of the answers received to the following statement: "Providing land to the Roma could help for their better social and economic integration, as well as contribute to the economic development of the villages" shows that the portion of those who disagree on using the opportunities for the integration of the Roma through providing them with land and creating the necessary preconditions for means of livelihood, hence boosting up the local economies of the villages, equals approximately $57 \%$, which is even higher than the skeptics towards refugees and immigrants. A good sign is that the percentage of those who agree (29.8\%) exceeds the share of the respondents of Roma origin $(3.4 \%)$, and those with ethnicity different from Bulgarian (11\%).

When analyzing the two-dimensional distributions between the chosen demographic characteristics and the chosen answers to the interview questions by applying the $\chi 2$-method, we receive the following statistical dependencies and the following cross-tabulations:

1. Residence (region) and the attitudes towards ethnic groups of Roma and Turks (for Roma: Pearson Chi-Square $<0.05$, Cramer's V $=0.471$; for Turks: Pearson Chi-Square $<0.05$; Cramer's $\mathrm{V}=0.312$ )

2. Residence (region) and acceptance of the statement "The settlement of refugees and immigrants could help to revive depopulated Bulgarian villages, by bringing in new business skills and cultural traditions" (Pearson ChiSquare $<0.05$; Cramer's V $=0.243$ )

3. Residence (region and the acceptance of the statement "Providing land to the Roma could help for their better social and economic integration, as well as contribute to the economic development of the villages" (Pearson Chi-Square $<0.05$; Cramer's V $=0.240$ ) 
4. Marital status and the attitude towards group of residents of countries outside EU (Pearson Chi-Square $<0.05$; Cramer's V $=0.368$ )

5. Education and attitudes towards refugees (Pearson Chi-Square $<0.05$; Cramer's V $=$ $0.470)$

6. Education and attitudes towards Roma (Pearson Chi-Square $<0.05$; Cramer's $\mathrm{V}=$ $0.626)$

7. Education and attitude towards the Bulgarian ethnic group (Pearson Chi-Square < 0.05, Cramer's V $=0.740$ )

8. Education and agreement with the statement "The settlement of refugees and immigrants could help to revive depopulated Bulgarian villages, by bringing in new business skills and cultural traditions." (Pearson Chi-Square < 0.05; Cramer's V $=0.390$ )

9. Education and acceptance of the statement "Providing land to the Roma could help for their better social and economic integration, as well as contribute to the economic development of the villages." (Pearson Chi-Square < 0.05; Cramer's V $=0.444$ )

Table 5 gives the results from the crosstabulation between the region, where the respondents live, and the corresponding answers on the researched topics.

Table 5-1 gives the two-dimensional distributions of the answers connected with the attitudes of living in a village with Roma population.

The group of respondents from the developed regions is characterized by low preference for cohabitation with the Roma population - 52.3 $\%$, although the total share of preference reaches almost $60 \%$. The people from lagging regions reject this cohabitation with almost $80 \%$. This is an illustration of the correlation between economic stability/development of a region and the decreased level of negative attitudes (and vice versa for lagging regions), also discussed by other authors $(9 ; 10)$. In lagging regions, these groups are seen as economic competitors for available limited number of workplaces and resources, i.e. as a potential threat. The connection between the level of development of the region as a decisive factor and the maintained level of tolerance is confirmed to a larger extent by the survey conducted by the Open Society Institute (12). According to the survey, the most tolerant region is the CentralSouth Region, and the least tolerant one is the North-East Region (12). Social distances are
GEORGIEVA-STANKOVA N., et al. also smaller in cities and more evident in smaller towns and villages (12).

Attitudes towards the other ethnic group (the ethnic Turkish) with the statistically proven connection with the level of development of the region are shown in Table 5-2. In this case, preferences for cohabitation are higher - in the developed region, the portion of positive attitudes exceeds $60 \%$, and in the lagging region - approximately 1 on every two (including those who have no preferences) will accept to live in a village that has residents of this ethnic group.

The level of acceptance of the respondents on the issue that there is an opportunity to revive depopulated Bulgarian villages by offering settlement to refugees and immigrants, is shown on Table 5-3. In the developed region, there is a predominance of disagreement $(52.3 \%)$, while the lagging region is more willing to believe in the revival of local economy, by bringing in the new business skills and cultural traditions of refugees and immigrants, although not showing complete conviction.

Table 5-4 reveals the specific standpoints of both types of regions on the statement regarding the provision of land to the Roma population for the needs of the economic development of the villages. In both regions, the level of disagreement is very high $-56.9 \%$ in the developed one and $60 \%$ in the lagging. These results, however, can be explained in two ways on the one hand, this attitude could be resulting from the attitudes towards the Roma population, as shown in Table 5-1, but demonstrated skepticism could also be explained by the existing pessimism about the future of Bulgarian villages and their economy.

It is interesting to note, that belonging to a certain social group according to marital status affects the acceptance of non- EU residents. Table 6 shows that family groups without children are quite specific in their low preference for the settlement of this type of residents - almost $90 \%$, which is not a rejection, but a sign of disconcert and doubt about the possible influence that foreign non-EU representatives might have on the way of life in the villages. Married people with children and single individuals are less afraid of the foreign culture and ethnicity - respectively $82.5 \%$ and $73.1 \%$ (including those without preferences), who declare their support for a possible cohabitation with this group. 
Table 5. Two-dimensional distribution of the opinions on the analyzed topics and region type

\begin{tabular}{|c|c|c|c|c|c|c|c|c|}
\hline \multicolumn{9}{|c|}{ 5-1 I would live in a village inhabited by: Roma } \\
\hline & \multirow[b]{2}{*}{ Region } & \multicolumn{6}{|c|}{ Possible answers } & \multirow[b]{2}{*}{ Total } \\
\hline & & \multirow{2}{*}{ 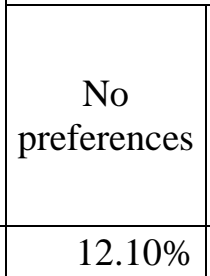 } & \multirow{2}{*}{$\begin{array}{c}\begin{array}{c}\text { Negative } \\
\text { preference }\end{array} \\
26.20 \%\end{array}$} & \multirow{2}{*}{$\begin{array}{c}\begin{array}{c}\text { Low } \\
\text { preference }\end{array} \\
52.30 \%\end{array}$} & \multirow{2}{*}{$\begin{array}{r}\begin{array}{c}\text { Moderate } \\
\text { preference }\end{array} \\
4.70 \% \\
\end{array}$} & \multirow{2}{*}{$\begin{array}{r}\begin{array}{c}\text { Considerable } \\
\text { preference }\end{array} \\
1.90 \%\end{array}$} & $\begin{array}{l}\text { Decisive } \\
\text { factor to } \\
\text { be of } \\
\text { only one } \\
\text { origin } \\
\end{array}$ & \\
\hline & \begin{tabular}{l|l}
1 & Developed \\
\end{tabular} & & & & & & $2.80 \%$ & $100 \%$ \\
\hline & \begin{tabular}{l|l}
2 & Lagging \\
\end{tabular} & $9.40 \%$ & $78.10 \%$ & $9.40 \%$ & $0.00 \%$ & $3.10 \%$ & $0.00 \%$ & $100 \%$ \\
\hline & & & I would live & in a village $i$ & habited by: & Turks & & \\
\hline \multirow{2}{*}{\multicolumn{2}{|c|}{ Region }} & \multicolumn{6}{|c|}{ Possible answers } & \\
\hline & & \begin{tabular}{c|c} 
No \\
preferences
\end{tabular} & $\begin{array}{l}\text { Negative } \\
\text { preference }\end{array}$ & $\begin{array}{l}\text { Low } \\
\text { preference }\end{array}$ & $\begin{array}{l}\text { Moderate } \\
\text { preference }\end{array}$ & $\begin{array}{l}\text { Considerable } \\
\text { preference }\end{array}$ & $\begin{array}{c}\text { Decisive } \\
\text { factor to } \\
\text { be of } \\
\text { only one } \\
\text { origin } \\
\end{array}$ & Total \\
\hline & \begin{tabular}{l|l}
1 & Developed \\
\end{tabular} & $10.40 \%$ & $24.50 \%$ & $41.50 \%$ & $12.30 \%$ & $8.50 \%$ & $2.80 \%$ & $100 \%$ \\
\hline & \begin{tabular}{l|l}
2 & Lagging \\
\end{tabular} & $12.50 \%$ & $56.20 \%$ & $18.80 \%$ & $9.40 \%$ & $3.10 \%$ & $0.00 \%$ & $100 \%$ \\
\hline \multicolumn{9}{|c|}{$\begin{array}{c}\text { 5-3 The settlement of refugees and immigrants could help to revive depopulated Bulgarian villages, } \\
\text { by bringing in new business skills and cultural traditions }\end{array}$} \\
\hline \multirow{2}{*}{\multicolumn{2}{|c|}{ Region }} & \multicolumn{4}{|c|}{ Possible answers } & \multirow{2}{*}{\multicolumn{2}{|c|}{ Total }} & \\
\hline & & I cannot say & I Disagree & $\begin{array}{l}\text { I agree to } \\
\text { some } \\
\text { extent }\end{array}$ & $\begin{array}{l}\text { I totally } \\
\text { agree }\end{array}$ & & & \\
\hline 1 & Developed & $13.80 \%$ & $52.30 \%$ & $29.40 \%$ & $4.50 \%$ & & & $100 \%$ \\
\hline \multirow{2}{*}{\multicolumn{2}{|c|}{2 Lagging }} & $0.00 \%$ & $45.70 \%$ & $42.90 \%$ & $11.40 \%$ & & & $100 \%$ \\
\hline & & $\begin{array}{l}\text { viding land } t \\
\text { as well as c }\end{array}$ & $\begin{array}{l}0 \text { the Roma c } \\
\text { ontribute to }\end{array}$ & $\begin{array}{l}\text { uld help for } \\
\text { he economic }\end{array}$ & $\begin{array}{l}\text { heir better } \\
\text { developmen }\end{array}$ & $\begin{array}{l}\text { cial and econo } \\
\text { of the villages }\end{array}$ & ic integ & tion, \\
\hline \multirow{2}{*}{\multicolumn{2}{|c|}{ Region }} & \multicolumn{4}{|c|}{ Possible answers } & \multirow{2}{*}{\multicolumn{2}{|c|}{ Total }} & \\
\hline & & $\begin{array}{l}\text { I cannot } \\
\text { say }\end{array}$ & I Disagree & $\begin{array}{c}\text { I agree to } \\
\text { some } \\
\text { extent }\end{array}$ & $\begin{array}{l}\text { I totally } \\
\text { agree }\end{array}$ & & & \\
\hline 1 & Developed & $15.60 \%$ & $56.90 \%$ & $23.90 \%$ & $3.60 \%$ & & & $100 \%$ \\
\hline 2 & Lagging & $2.90 \%$ & $60.00 \%$ & $22.90 \%$ & $14.20 \%$ & & & $100 \%$ \\
\hline
\end{tabular}

Table 6. Two-dimensional distribution of the opinions about non-EU residents and marital status

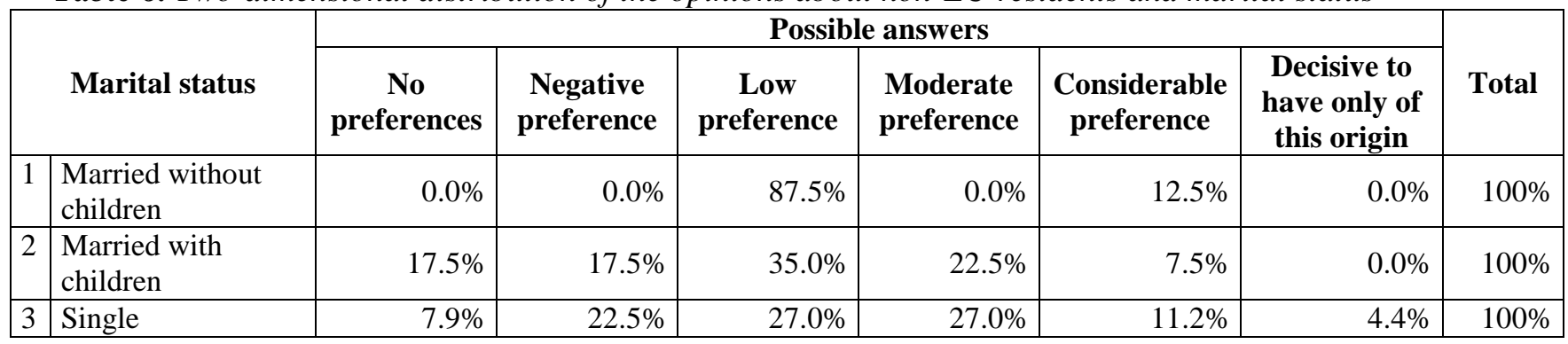


Table 7-1 shows the differences in attitudes with regard to living together with refugees depending on the educational level of the interviewed. Judging by the average value that states disagreement for living together with refugees (shown in Table 3), we could further specify that the strongest non-acceptance comes from people with college education $(62.5 \%$ ), and the highest level of acceptance from people with secondary school education - cohabitation with refugees is supported by $59.6 \%$ (including those with no preferences).

According to the results shown in Table 7-2, there is a similar tendency for the Roma - people with secondary education have the highest acceptance level when it comes to cohabitation with Roma$67.4 \%$ (including people with no preferences for any ethnicity), unlike the group of people with college education, of which three quarters reject the possibility for living in a village with Roma. However, we should point out that the group of college graduates takes a smaller portion of the respondents - barely $6 \%$, and people with secondary education take $68 \%$, which differs from the educational structure of the working-age population in Bulgaria, and creates additional interest in researching the educational structure of the existing village population, but also of people who intend to migrate in these populated areas.

The highest correlation is between the educational characteristics and the requirements for Bulgarian presence in the villages - Table 7-3. Graduates with higher education gravitate around values in the upper part of the preference scale - from Moderate preference to Decisive for a choice of village with only Bulgarians. People with secondary school education have higher fluctuations in the answers provided and $7.1 \%$ of them even state that they do not prefer villages with concentrated ethnic Bulgarian population. Their share is lower than the share of respondents with ethnicity different than Bulgarian (11\%),

which leads us to the conclusion that the better part of the negatively orientated towards a predominant part of the Bulgarian population, could be referred to the non-Bulgarian ethnic groups.

The influence of education over the opinions regarding "The settlement of refugees and immigrants could help to revive depopulated Bulgarian villages, by bringing in new business skills and cultural traditions" is shown in Table 74. A quarter of the college graduates agree completely with this statement, while one third of the people with higher and secondary education have certain doubts and partially accept this statement, although we should point out that more than $50 \%$ of these two educational groups completely reject the possibility of reviving Bulgarian villages with the help of refugees and immigrants.

Table 7-5 portrays the results concerning the idea to provide land to the Roma with the purpose of their better integration and business opportunities in the villages. This idea was rejected by $60 \%$ of the people with secondary education and by $57 \%$ of the people with higher education, while a quarter of the college graduates only partially accepted this idea, another $38 \%$ cannot decide; unlike secondary and higher education graduates, who state their opinion more decidedly - the percentage of those who cannot decide is between $14 \%$ and $2.9 \%$.

These results regarding the relationship between education and tolerance contradict the research conducted by the Open Society Institute 11). Education is an important factor in terms of marriage and spatial categories (cohabitation, visits). It is believed that the better educated a person is, the more tolerant is his/her attitude towards ethnic minorities (11). According to Pamporov, there are considerable differences in the attitudes of people with secondary and primary or lower level of education. The current research shows an inverse dependency: the most intolerant are people with higher education, and those with college education, while people with secondary school education are more likely to live together with other ethnic groups. We could search for an explanation for this, on the one hand, in the methodology used in this research, but an explanatory hypothesis for this phenomenon could be the possible lack of social contacts of the higher educational levels, and the social position occupied by them, with representatives of the Roma, ethnic Turkish, immigrant or refugee communities. The lower social (and educational) strata are more likely to have more frequent contacts with the above-mentioned groups, because of their shared experience and social position, which leads to a higher level of tolerance and acceptance of others.

The educational level of the respondents has the strongest influence over the stated opinions.

Table 7 shows the two-dimensional distributions, where the inter-dependability (correlation) is statistically proven. 
Table 7. Two-dimensional distribution of the opinions on refugees depending on the educational level

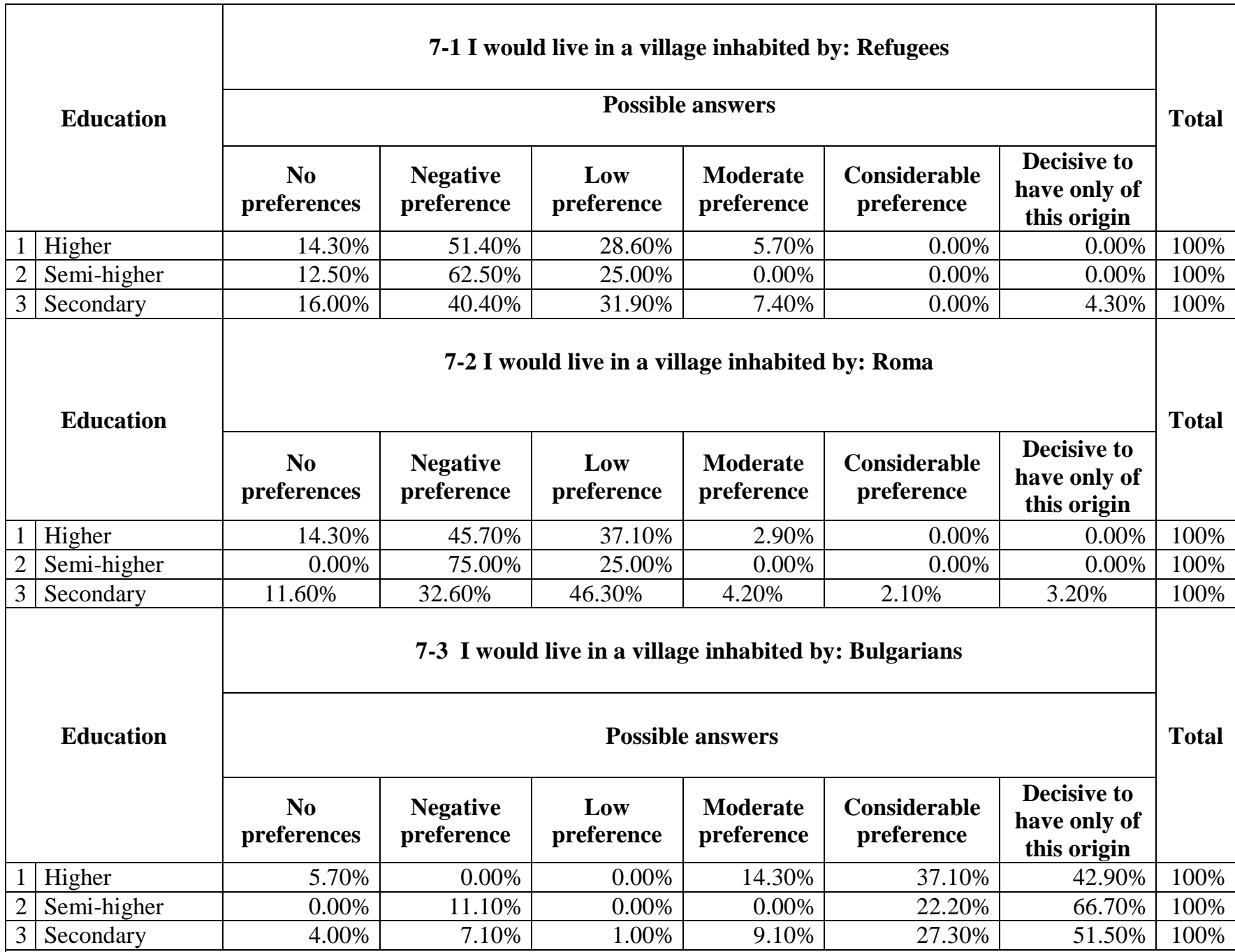

7-4 The settlement of refugees and immigrants could help to revive depopulated Bulgarian villages, by bringing in new business skills and cultural traditions

\begin{tabular}{|c|c|c|c|c|c|c|}
\hline \multirow{2}{*}{\multicolumn{2}{|c|}{ Education }} & \multicolumn{4}{|c|}{ Possible answers } & \multirow[b]{2}{*}{ Total } \\
\hline & & I cannot say & I disagree & I agree to some & I totally & \\
\hline 1 & Higher & $8.60 \%$ & $54.30 \%$ & $31.40 \%$ & $5.70 \%$ & $100 \%$ \\
\hline 2 & Semi-higher & $0.00 \%$ & $37.50 \%$ & $37.50 \%$ & $25.00 \%$ & $100 \%$ \\
\hline 3 & Secondary & $12.00 \%$ & $51.00 \%$ & $33.00 \%$ & $4.00 \%$ & $100 \%$ \\
\hline
\end{tabular}

7-5 Providing land to the Roma could help for their better social and economic integration, as well as contribution to the economic development of the villages

\begin{tabular}{|c|c|c|c|c|c|c|}
\hline \multirow{2}{*}{\multicolumn{2}{|c|}{ Education }} & \multicolumn{4}{|c|}{ Possible answers } & \multirow[b]{2}{*}{ Total } \\
\hline & & I cannot say & I disagree & $\begin{array}{c}\text { I agree to some } \\
\text { extent }\end{array}$ & $\begin{array}{c}\text { I totally } \\
\text { agree }\end{array}$ & \\
\hline 1 & Higher & $2.90 \%$ & $57.10 \%$ & $25.70 \%$ & $14.30 \%$ & $100 \%$ \\
\hline 2 & Semi-higher & $37.50 \%$ & $37.50 \%$ & $25.00 \%$ & $0.00 \%$ & $100 \%$ \\
\hline 3 & Secondary & $14.00 \%$ & $60.00 \%$ & $23.00 \%$ & $3.00 \%$ & $100 \%$ \\
\hline
\end{tabular}




\section{DISCUSSION AND CONCLUSION}

Ethnic and immigrant communities represent an important social and economic resource for Bulgarian villages and the creation and strengthening of existing opportunity structures, namely, the development and introduction of successful integration policies, could help for their social integration and contribute to the re-population and revival of some of the villages and rural areas.

Unfortunately, their adequate utilization as a resource for the country meets considerable difficulties, among which at this stage are existing negative social attitudes. This research shows considerable preference towards the idea of populating the villages with Bulgarian citizens and permanent tendencies with regard to social distances between different ethnic groups. However, we could not fail to acknowledge that unlike other surveys, there is a higher percentage of acceptance of the Roma and ethnic Turkish groups, including respondents without preferences, respectively approximately $62 \%$ acceptance for the Roma and approximately $69 \%$ for the ethnic Turks.

An illustration of the connection between economic stability / regional development and a lower level of negative attitudes is confirmed by the mass rejection of cohabitation with Roma in the lagging regions.

There is also an apparent negative attitude towards refugees (approximately 60\%), and even those stating preference, belong to the group expressing the lowest level of willingness for such cohabitation. Nevertheless, we should search for certain potential for support in those, who have no preference regarding the ethnic structure of the village population. The lagging region is more prone to counting on the refugees and immigrants for reviving the local economies, by bringing in new business skills and cultural traditions, although without much confidence.

Least afraid of the unfamiliar culture and ethnicity are families with children, who declare their support for a possible cohabitation with such groups, which probably is a result of gained life experience in raising children and empathy towards refugee families in need. Half of the respondents voice their disagreement with the statement "The settlement of refugees and immigrants could help to revive depopulated Bulgarian villages, by bringing in new business skills and cultural traditions". The share of those who have not stated any opinion (10\%) could be seen as a possible field for further work and
GEORGIEVA-STANKOVA N., et al. development through awareness-raising programmes for influencing public attitudes.

The percentage of people, who disagree on the possibilities arising from Roma integration, by giving them land and creating suitable conditions for making a living, and hence the revival of local economies, is approximately $57 \%$. This is an expression of skepticism, not only regarding the contribution of the Roma in agricultural activity, but is also related to the discouraging tendencies concerning the revival of depopulated villages.

Statistically speaking, the educational level of the respondents has the strongest influence on expressed opinions. It is interesting to note that people with secondary school education are most willing to accept cohabitation with Roma and ethnic Turks. People with higher education express agreement on statements, such as "rather preferred" to "decisive" preference for ethnic Bulgarians, when choosing a village for settling, which contrasts the results of other surveys, revealing the connection between education and tolerance.

Furthermore, there is a considerable share of the higher-education group in the present research, who completely reject the idea of reviving Bulgarian villages with the help of refugees and immigrants, or by providing land to the Roma. This could be explained not only by the problem of social distances, but also by the failure of all existing measures for eliminating negative demographic processes in Bulgarian villages.

Integration faces many obstacles, some originating from deficiencies in opportunity structures in the macrosocial environment and governmental institutions, others from the capacity and potential of these groups to integrate, or from adequate recognition of the potential benefits deriving from this. State institutions are the ones that should have the leading role in changing public attitudes and explaining the benefits of integration. Better coordination between different authorities is an additional precondition. Of primary importance will be the implementation of programs for a positive change in social attitudes towards ethnic and immigrant communities and overcoming social distances. The media can also play a considerable role, as one of the main socializing institutions, for overcoming negative attitudes, building trust and social solidarity - contributing to the required social capital for successful integration policies. 
The expected measures for harnessing all human resources in the creation of thriving residential structural units on the territory of the country and the employment of the existing facilities of depopulated areas, include strengthening of the institutional regime in the country - laws, statutory documents and culture, that might ensure improvement in integration and inclusion policies, more efficient and productive procedures and actions for the complete revitalisation of Bulgarian villages, overall prosperity of the national economy and quality of life.

\section{REFERENCES}

1. BTA (Bulgarian Telegraphic Agency), 2013. Vidin and Montana depopulate fastest. Vesti.bg.http://www.vesti.bg/vidini-montana-se-obezliudiavat-naj-byrzo5995843. Accessed 10 March 2015.

2. Programme for Rural Development (20142020).

3. NSI (National Statistical Institute), 2013. Demographic processes in 2013 (final results).

http://www.nsi.bg/sites/default/files/files/pr essreleases/Population2013_AUIT2RS.pdf. Accessed 12 Feb. 2015.

4. Volery T, 2007. Ch.3. Ethnic Entrepreneurship: A Theoretical Framework. In: Dana Léo Paul (Hrsg), Handbook of research on ethnic minority entrepreneurship: a Co-evolutionary View on Resource Management. Edward Elgar, Cheltenham, p 30-41.

5. Fregetto E, 2004. Immigrant and ethnic entrepreneurship: a U.S. perspective. In: Welsch HP (ed),

6. Pütz R, 2003. Culture and entrepreneurship - remarks on transculturality as practice. Tijdschrift voor Economische en Sociale Geografie. 94(5): 554-63.

7. Waldinger RH, Aldrich and Ward R, 1990. Opportunities, group characteristics and strategies. In: Waldinger R, Aldrich $\mathrm{H}$ and Ward R (eds) Ethnic entrepreneurs: Immigrant business in industrial societies. Sage, London, p 13-48.

8. Boissevain J, Blauschkee J, Grotenberg H, Joseph I, Light I, Sway M, Waldinger R and Werbner P. 1990. Ethnic entrepreneurs and ethnic strategies. In: Waldinger $\mathrm{R}$, Aldrich $\mathrm{H}$ and Ward $\mathrm{R}$ (eds), Ethnic entrepreneurs: Immigrant business in industrial societies. Sage, London, p 13157.

9. Tomova I, 1995. The Gypsies in the transition period. International Centre for Minority Studies and Intercultural Relations (ICMSIR), Sofia.
GEORGIEVA-STANKOVA N., et al.

10.Lukassen L and Willems W, 2001. The weakening of well-ordered societies. Gypsies in Europe, the Ottoman Empire and India 1400-1914. Paper presented at NIAS - Conference "Accommodating cultural and religious differences," Wassenaar, 5-7 July 2001.

11.Pamporov A, 2007. Ethnic distances in Bulgaria in 2007. In: Mitev P-E, Kotseva T and Mihova, G (eds) Young people in European Bulgaria. Centre for Population Studies - Bulgarian Academy of Sciences, Sofia, p 266-285.

12.Pamporov A, 2009. Social distances and ethnic stereotypes for minorities in Bulgaria. Open Society Institute (OSI), Sofia.

13.Pamporov A, 2011. Déjà vu: disappearing minorities.

http://www.bghelsinki.org/bg/publikacii/ob ektiv/aleksei-pamporov/2011-07/dejavuizchezvashite-malcinstva/. Accessed 5 April 2015.

14.Kanev K, 1997. Ethnic prejudice in Bulgarian society. In: International conference "Minorities in the media: reality and prejudices," Human Rights Project (HRP), Sofia. 25-26 October 1997, p 11-23.

15.Ethnic Prejudices, 1998. Gitane. 09: 10-11.

16.NSI (National Statistical Institute), 2011. Census of people and housing in Bulgaria. Population by ethnicity and native language.

http://censusresults.nsi.bg/Census/Reports/2 /2/R9.aspx. Accessed 4 March 2015.

17. National Roma Integration Strategy of the Republic of Bulgaria (NRISRB) (20122020).

http://www.strategy.bg/StrategicDocuments /View .aspx ?lang=bg-BG\&Id=726.

Accessed 9 March 2015.

18.Fraser A, 1992. The Gypsies (The Peoples of Europe). Blackwell Publishers, Oxford.

19. Nemeth D, 1986. Service Nomads: Interim Masters of Imperfect Markets. Nomadic Peoples. 21/22: 135-151.

20.Okely J, 1996. Own and Other Culture. Routledge, London. http://ethnos.bg/data/file/Documents/Resear ches/July_2009_SocialDistancesReport.pdf. Accessed 2 April 2015.

21.Marushiakova E and Popov V, 1997. The Gypsies in Bulgaria. "Club '90" Publishers, Sofia.

22.Ivanova $\mathrm{E}$ and Krastev V, 2006. On the Long road... Life with the others (history, ethnosocial structure, life-style and culture of Gypsy groups). Kota Publishers, Stara Zagora. 
23.Bogdanov L and Angelov G, 2006. Roma integration in Bulgaria: necessary reforms and economic effects. Open Society Foundation, Sofia. http://www.osf.bg/cyeds/downloads/L.Bog danov_G.Angelov_Politiki_08_06_ENG.pd f. Accessed 15 April 2015.

24. Maeva M, 2005. Bulgarian Turks and the European Union. In: Rusu H and Voicu B (eds) EU integration process from EAST to EAST: Civil society and ethnic minorities in a changing world. Proceedings from a round table for young social scientists, Sibiu, Psihomedia Publ. House, p 119-126. http://www.balkanethnology.org/files/librar y/Mila/Turks\%20and\%20EU\%20Eng.pdf. Accessed 22 March 2015.
GEORGIEVA-STANKOVA N., et al. 25.Mitev P-E and Kovacheva C, 2014. Young people in European Bulgaria. A sociological portrait 2014. Friedrich Ebert Foundation,

Sofia. http://www.fes.bg/files/custom/library/2014 /Mladite_hora_v_evropeiska_Balgaria.pdf. Accessed 15 March 2015.

26. Kamenova D, 2013. Refugees - "a person of the year" or a "problem of the year" for Bulgaria?

http://cobra.superhosting.bg/ schoolof/ima ges/pdf/refugees\%20researchd.kamenova\% 20bsop.pdf . Accessed 2 April 2015.

27.IME (Institute for Market Economics), 2014. Regional profiles: development factors. 